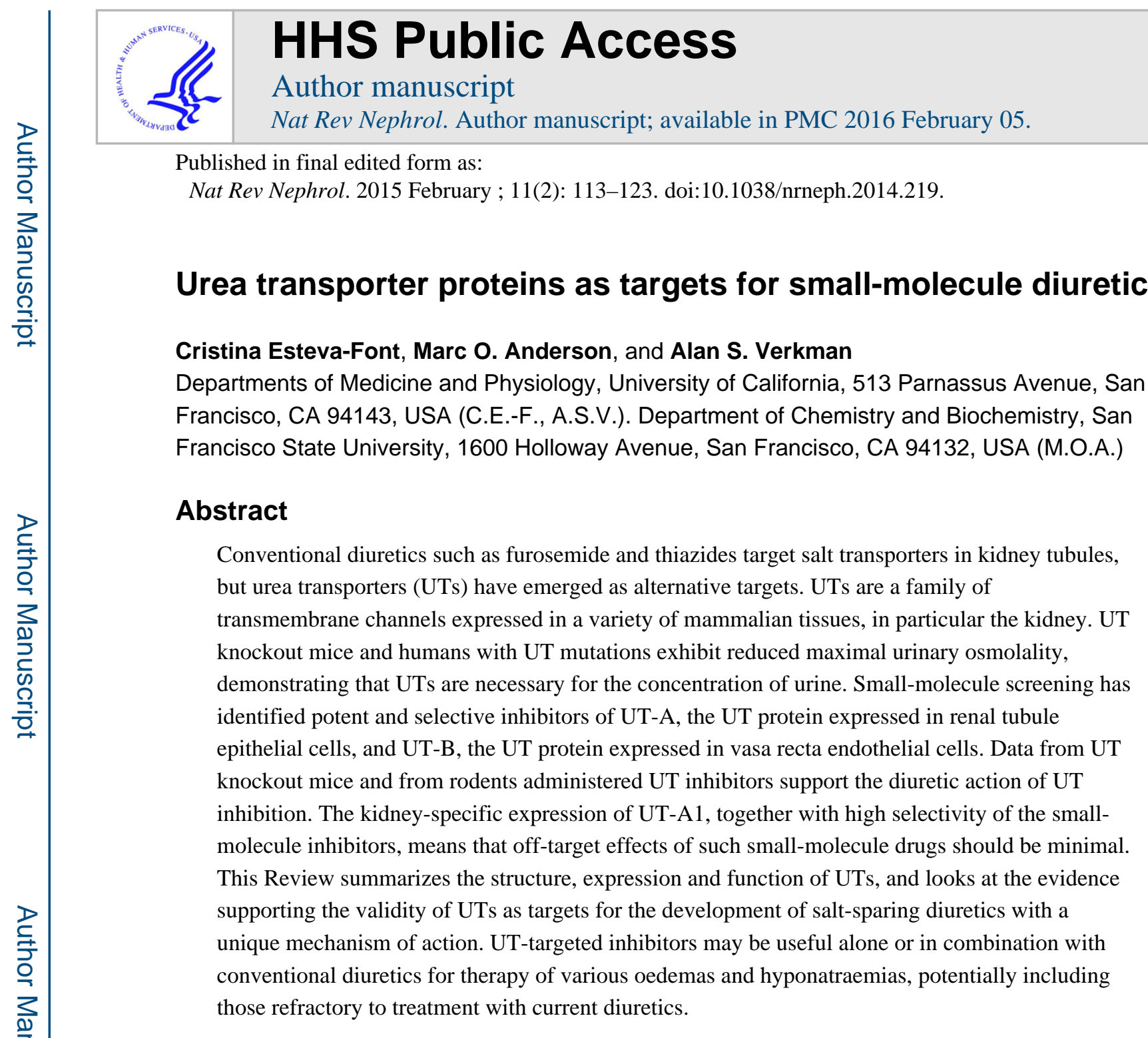

\title{
Introduction
}

Urea is the end-product of nitrogen metabolism in mammals; it is generated mainly in the liver, excreted by the kidney, and highly concentrated in urine compared with levels in blood. A central role for urea and urea transport in the urinary concentrating mechanism was first proposed by Gamble and colleagues in $1934,{ }^{1}$ based on the observation that increased urine concentration in rats resulted from urea loading. Urea transporter (UT) proteins, which facilitate the passive transport of urea driven by a concentration gradient across some cell plasma membranes, are now known to be essential in the urinary concentrating mechanism.

\footnotetext{
Correspondence to: A.S.V. alan.verkman@ucsf.edu.

Competing interests

C.E.-F., M.O.A. and A.S.V. declare that they are named inventors on patent applications for urea transporter screening methods and small-molecule urea transporter inhibitors. Patent rights are assigned to the authors' respective institutions, and patents have not yet been licensed.

Author contributions

C.E.-F., M.O.A. and A.S.V. researched data for the article, provided substantial contributions to discussions of content, and wrote the article, and reviewed and/or edited the manuscript before submission.
} 
It has long been appreciated that urea permeability $\left(\mathrm{P}_{\text {urea }}\right)$ varies widely between different cell membranes; $; 2,3$ the high $\mathrm{P}_{\text {urea }}$ of human erythrocyte membranes $\left(4-10 \times 10^{-4} \mathrm{~cm} / \mathrm{s}\right)^{4}$ compared with artificial lipid bilayers $\left(\sim 4 \times 10^{-6} \mathrm{~cm} / \mathrm{s}\right)^{5,6}$ suggested the existence of facilitated urea transport. Similarly, studies of rabbit kidneys have shown high transepithelial $\mathrm{P}_{\text {urea }}\left(\sim 2 \times 10^{-5} \mathrm{~cm} / \mathrm{s}\right)$ in isolated perfused cortical collecting ducts, ${ }^{7}$ and very high $\mathrm{P}_{\text {urea }}\left(\sim 4 \times 10^{-4} \mathrm{~cm} / \mathrm{s}\right)$ in the inner medullary collecting duct (IMCD). ${ }^{8}$

Early molecular studies suggested the existence of UT proteins because urea transport in Xenopus oocytes increased after the cells were injected with mRNA from toad urinary bladder, a tissue that has high $\mathrm{P}_{\text {urea }} \cdot{ }^{9}$ The first UT protein was identified in rabbit kidneys in 1993 by using expression cloning; ${ }^{10}$ subsequent work has identified and characterized homologous UTs from other mammals and lower organisms, greatly advancing our understanding of UT biology, particularly in the kidney. This Review discusses these discoveries and looks at emerging evidence from experiments with UT knockout mice and small-molecule UT inhibitors, which show that UT inhibitors have clinical potential as saltsparing diuretics, or 'urearetics', that have a unique mechanism of action. This mechanism is the disruption of the countercurrent multiplication mechanism for urinary concentration that leads to a diuretic response.

\section{UT proteins}

\section{Molecular genetics}

Mammalian UT proteins are encoded by two genes that are arranged in tandem: SLC14A1 and SLC14A2. In humans, these genes are located $\sim 50 \mathrm{~kb}$ apart on chromosome $18 .{ }^{11,12}$ The SLC14A1 gene consists of 11 exons and encodes two variants of UT-B, UT-B1 and UT-B2, which are splice variants of the $S L C 14 A 1$ gene ${ }^{13,14}$ that show $100 \%$ homology except for an additional 55 amino acids in the N-terminus of UT-B2. ${ }^{15}$ In this Review, we use the term UT-B to refer to both splice variants, and only distinguish between the splice variants when their expression or functions differ.

The SLC14A2 gene consists of 26 exons and encodes six UT-A isoforms, which are under the control of two distinct promoters: UT-Aa and UT-A $\beta .{ }^{16,17}$ UT-A1, UT-A3, UT-A4, UTA5 and UT-A6 are transcribed from the UT-Aa promoter, which is located upstream of exon 1 , whereas UT-A2 is transcribed from the internal UT-A $\beta$ promoter. ${ }^{18}$ The entire length of the SLC14A2 gene encodes UT-A1, which consists of 930 amino acids; the other five isoforms share different regions of this coding sequence (Figure 1). ${ }^{19-21}$ UT-A1, UTA2 and UT-A3 have all been identified in mice, rats and humans, whereas UT-A4 has only been identified in rats, UT-A5 only in mice and UT-A6 only in humans. ${ }^{19,22,23}$ UT-B has $>60 \%$ homology with UT-A2. ${ }^{24}$

\section{Molecular structure}

The first X-ray crystal structure of a UT that was solved was that of the bacterial protein dvUT, a functional homologue of mammalian UTs from Desulphovibrio vulgaris. ${ }^{25}$ Structures were determined for dvUT both alone and co-crystallized with the urea analogue dimethylurea (Protein Data Bank IDs 3K3G and 3K3F, respectively). The same group subsequently solved X-ray crystal structures of the mammalian UT-B from Bos taurus, both 
alone and co-crystallized with selenourea (Protein Data Bank IDs 4EZC and 4EZD, respectively; Figure 2). ${ }^{26}$ These studies showed that the quaternary structures of dvUT and bovine UT-B are similar, with both forming homotrimers (Figure 2a); size-exclusion chromatography suggested that human UT-B also exists as a homotrimer. Whether or not the UT-A isoforms also exist as homotrimers is still unknown. A dimeric structure of UT-A1 was proposed on the basis of chemical crosslinking, but the identity of the species as a homodimer or hetero-oligomer was not established. ${ }^{27}$ Although UT-A1 and UT-A3 are coexpressed in the IMCD, immunoprecipitation suggests that they do not oligomerize. ${ }^{28}$

Bovine UT-B and dvUT each contain two homologous halves that fold to form the complete channel (Figure 2b), and it has been postulated that the homologous halves descend from a common ancestral gene that duplicated at a time near to the divergence of eukaryotes from prokaryotes. ${ }^{29}$ Each UT-B half contains five transmembrane helices (T1a-T5a and T1b$\mathrm{T} 5 \mathrm{~b})$ and a tilted helix $(\mathrm{Pa}$ and $\mathrm{Pb})$ that is approximately half the length of the membranespanning helices. The N-termini and C-termini of dvUT and UT-B are cytoplasmic, as confirmed by topogenic signal analysis ${ }^{30}$ and immunoadsorption experiments with human UT-B. ${ }^{31}$

The UT-A isoforms UT-A2, UT-A3 and UT-A4 are each predicted to have a similar molecular structure to UT-B: 10 transmembrane domains with two internal hydrophobic repeats, linked by an extracellular connecting loop and with intracellular N-termini and Ctermini. The largest UT-A isoform, UT-A1, consists of this structure duplicated. ${ }^{13,32}$

UT-B contains an amphipathic pore region formed by the association of the two homologous halves (Figure 2c). The UT-B selectivity filter is thought to involve three regions that line the central pore: the $S_{0}, S_{i}$ and $S_{m}$ sites. ${ }^{26}$ The $S_{0}$ and $S_{i}$ sites, which are on the extracellular and cytoplasmic sides respectively, form a ladder of main-chain and side-chain oxygen atoms that are able to form hydrogen bonds and that interact with the polar urea molecule. The $\mathrm{S}_{\mathrm{m}}$ site serves as a central constriction of the channel.

When co-crystallized with bovine UT-B, the urea analogue selenourea interacts with the selectivity filter by hydrogen bonding with Asn227 at the $S_{0}$ site, and with Asn63 at the $S_{i}$ site (Figure 2c). The $S_{m}$ site is relatively narrow and lined by the hydrophobic side chains of Thr172 and Thr334, which, in addition to serving as a steric constriction, might desolvate urea as it passes through the pore. A Thr172Val mutation increases steric hindrance at the constriction site and results in reduced $\mathrm{P}_{\text {urea }}$, whereas Thr172Ser, Thr334Ser, and Thr172Ser-Thr334Ser mutations reduce steric hindrance and slightly increase $\mathrm{P}_{\text {urea }}{ }^{26}$ Interestingly, despite the narrow and desolvating $\mathrm{S}_{\mathrm{m}}$ constriction site, UT-B can conduct water, whereas the UT-A isoforms cannot. ${ }^{33-35}$

Other small-molecule analogues of urea are also able to traverse the UT-B channel, including formamide, acetamide, methylurea, methylformamide, ammonium carbonate and acrylamide. ${ }^{36}$ Molecular dynamics simulations that used the technique of umbrella sampling concluded that urea traverses the channel with minimal rotation, allowing it to continuously maintain hydrogen bonding interactions with the ladder of hydrogen-bond-accepting groups, and preventing substantial alteration of the UT-B structure. ${ }^{26}$ 


\section{Tissue expression}

Most UTs are expressed in the kidney (Figure 3), where their role in the urinary concentrating mechanism has been well studied. UT-A1 is expressed on the apical membranes and UT-A3 on the basolateral membranes of cells in the IMCD, which is the most urea-permeable segment of the nephron. ${ }^{22,37,38}$ One study reported that UT-A3 is also localized to the apical membranes of cells in the IMCD after vasopressin administration. ${ }^{39}$

UT-A2 is expressed in the thin descending limbs of the short loop nephrons in the outer medulla and in the distal part of long loop nephrons in the inner medulla. ${ }^{40}$ UT-A4 has been reported in renal medulla only in rats, and its precise cellular localization is not known. ${ }^{22}$ UT-B, including both splice variants, is expressed in endothelial cells of the descending vasa recta. $^{41,42}$

Some UTs are also expressed outside of the kidney (Box 1); knowledge of extrarenal UT expression sites and function is important in drug discovery to identify potential off-target, extrarenal effects of UT inhibition.

\section{Box 1}

\section{Extrarenal expression of mammalian UT proteins}

- UT-B1: bladder, brain, colon, ear, erythrocyte, heart, liver, lung, pancreas, prostate, skeletal muscle, small intestine, testis, thymus, spleen

- UT-B2: brain (human), rumen (bovine), thymus (mouse)

- UT-A1: cochlea

- UT-A2: heart, liver

- UT-A3: cochlea, inner medullary collecting duct

- UT-A4: renal medulla (rat)

- UT-A5: testis (mouse)

- UT-A6: colon (human)

Abbreviation: UT, urea transporter.

Extrarenal expression of UT-B splice variants differs between tissues; UT-B1 is expressed more widely than UT-B2, which has only been detected in the brain of humans. ${ }^{15,41}$ Immunocytochemistry has demonstrated the localization of UT-B1 to villous epithelium in the small intestinal, gastric glandular epithelium ${ }^{43}$ and colonic crypt epithelium ${ }^{44,45}$ in the digestive tract, ependymal cells and astrocytes in the brain, aortic endothelia cells, ${ }^{12,41,46}$ and Sertoli cells in the testes. ${ }^{47}$ UT-A isoforms have limited extrarenal expression, but UT$\mathrm{A} 1,{ }^{48}$ UT-A2, ${ }^{49}$ UT-A $3{ }^{48}$ and UT-A $6{ }^{21}$ have been detected in extrarenal tissues in humans, whereas the UT-A5 transcript is expressed in peritubular myoid cells in the seminiferous tubules in mouse testes. ${ }^{19,50}$

Potential roles of extrarenal UTs have been proposed. UT-A2 in liver and heart may facilitate efflux of metabolically generated urea, ${ }^{49,51,52}$ and UTs in the inner ear have been 
postulated to facilitate urea transport between the endolymph and perilymph, contributing to fluid homeostasis. ${ }^{48}$ Phenotype studies on UT-B knockout mice have revealed neuropsychiatric, ${ }^{53}$ cardiac conduction, ${ }^{54,55}$ bladder $^{56}$ and testicular ${ }^{57}$ abnormalities, although the relevance of these phenotype findings is unclear, both because they lack plausible mechanisms, suggesting secondary effects, and because there are no studies of humans with loss-of-function mutations in UT-B that report extrarenal abnormalities.

\section{Regulation}

Vasopressin regulation of $\mathrm{P}_{\text {urea }}$ in the collecting duct was described before the identification of UTs; $;{ }^{58-60}$ vasopressin is now known to be a major regulator of UT-A1 and UT-A3 in the IMCD. Vasopressin binding to V2 receptors causes elevation of cAMP, activation of protein kinase A, and phosphorylation of UT-A1 and UT-A3. ${ }^{28,61-63}$ Serine phosphorylation of UTA1 and UT-A3 is involved in their accumulation in the plasma membrane and is associated with an increase in IMCD $\mathrm{P}_{\text {urea }}{ }^{64-66}$ Independently of vasopressin, hypertonicity also increases IMCD $\mathrm{P}_{\text {urea }}$ by UT-A1 and UT-A3 phosphorylation and membrane targeting, ${ }^{39,67}$ via mechanisms involving a calcium-dependent protein kinase $\mathrm{C}^{68}$

Recent data also suggest the involvement of caveolin, snapin and actin in apical membrane UT targeting. ${ }^{69}$ UT-A1 degradation, which involves the lysosome-proteasome system, might regulate UT-A1 expression at a post-transcriptional level. ${ }^{70}$

\section{Non-mammalian UTs}

UTs are found not only in mammals, but also in non-mammalian organisms including bacteria, plants and fish. A brief discussion of non-mammalian UTs is informative in understanding the wide-ranging functions of UTs, some of which are relevant in mammals.

Bacterial UTs can be divided into three distinct functional classes: pH-independent, protongated and ATP-activated. The bacterial UT protein Yut, found in Yersinia, is $\mathrm{pH}-$ independent and homologous to mammalian UTs, showing $22 \%$ sequence identity to human UT-A1 $;{ }^{71,72}$ for comparison, dvUT shows $35 \%$ sequence identity to human UT-B. ${ }^{25}$ UreI from Helicobacter pylori, a bacterium that survives in the highly acidic gastric environment, is a $\mathrm{H}^{+}$-gated UT. H. pylori uses UreI to transport urea into the cytoplasm, where it is then hydrolysed to form $\mathrm{NH}_{3}$ and $\mathrm{CO}_{2},{ }^{71,73}$ the $\mathrm{NH}_{3}$ and $\mathrm{CO}_{2}$ are transported to the periplasm, where $\mathrm{NH}_{3}$ neutralizes acid, and $\mathrm{CO}_{2}$ (upon conversion to bicarbonate) buffers periplasmic $\mathrm{pH}$ to $\sim 6.1 .^{73}$ Some bacterial UTs belong to the ATP-binding cassette (ABC) class of transporters, meaning that urea transport by these transporters is accompanied by ATP hydrolysis. The ABC class of UTs is used by the soil bacterium Corynebacterium glutamicum and various species of cyanobacteria, in which imported urea is hydrolysed by urease and used as a catabolic nitrogen source..$^{71}$

One class of plant aquaporins called tonoplast intrinsic proteins, which were identified in Arabidopsis, show pH-independent and phloretin-sensitive urea transport. ${ }^{74}$ Arabidopsis also expresses a high-affinity $\mathrm{H}^{+}$-urea symporter called AtDUR3, which belongs to a family of $\mathrm{Na}^{+}$-solute symporters. ${ }^{75}$ Although only limited information is available, increased 
expression of AtDUR3 has been observed in Arabidopsis seedlings, suggesting that urea transport might be involved in early plant development. ${ }^{75}$

Of non-mammalian vertebrates that express UTs, fish have received the most attention. ${ }^{76,77}$ An interesting difference between fish and mammals is that fish lack an erythrocyte UT. ${ }^{76}$ In teleosts, UTs, together with ammonia transporters, seem to be involved in nitrogen excretion through the gills, ${ }^{76}$ whereas in elasmobranches, UTs in the kidney and gill help to retain urea against the concentration gradient set up by the surrounding water. ${ }^{76,78}$ As would be expected, fish UTs have greater homology than do bacterial UTs to mammalian UTs; for example, the UT of Danio rerio (zebrafish) has $63 \%$ sequence identity to human UT-A2. In 2005, a new UT (named UT-C) was identified in the proximal tubule of kidneys in seawater eel, which is the first example of a UT expressed in proximal tubule. ${ }^{79}$

\section{UTs in kidney function}

\section{UTs and the urinary concentrating mechanism}

Concentration of urine by the kidney involves a counter-current multiplication mechanism, in which the anatomical configuration of the tubules and vasa recta permits countercurrent flow and intrarenal urea recycling, resulting in a hypertonic inner medulla. Urea has a central role in this mechanism. ${ }^{80,81}$ The IMCD, which expresses UT-A1 and UT-A3, is responsible for urea reabsorption during antidiuresis; this reabsorption is needed to maintain a hypertonic medullary interstitium. The fenestrated ascending vasa recta, which is highly permeable to urea, facilitates transfer of urea from the inner to the outer medulla, where its concentration is lower. Interstitial urea coming from the ascending vasa recta is partially reabsorbed by the non-fenestrated descending vasa recta, which expresses UT-B, and the thin descending limb of Henle, which expresses UT-A2, by a countercurrent exchange mechanism in which urea recycling conserves renal urea. ${ }^{80-82}$

Although these basic processes are probably correct (at least qualitatively), many questions remain about the role of urea in countercurrent multiplication and exchange mechanisms, as mathematical models are unable to predict the actual magnitude of urinary concentration in mammals. Current understanding of the role of urea and UTs in the urinary concentrating mechanism is discussed in a recent review. ${ }^{83}$

\section{Lessons from UT knockout mice}

The first UT knockout mouse was generated in 2002 by targeted UT-B gene disruption. ${ }^{84}$ UT-B knockout mice show a modest, $\sim 50 \%$ increase in fluid intake and urinary output compared with wild-type mice, and manifest a mild reduction in maximum urinary osmolality (1,500 mOsm/ $/ \mathrm{kg} \mathrm{H}_{2} \mathrm{O}$ versus 2,000 mOsm/ $/ \mathrm{kg} \mathrm{H}_{2} \mathrm{O}$ in wild-type mice). The knockout mice show a more than twofold reduction in the urine-to-plasma ratio of urea compared with that of wild-type mice, indicating a reduced capacity of the kidney to concentrate urea above its blood level. This defect suggests that urea recycling in the descending vasa recta is impaired; the greater quantities of urea returned to the general circulation result in reduced inner medullary hypertonicity and urinary concentration. ${ }^{84,85}$ 
Mice that lack both UT-A1 and UT-A3 show a marked defect in urinary concentrating function. ${ }^{86}$ With a normal diet, UT-A1/3 knockout mice have more than a twofold increase in fluid intake and an approximately threefold increase in urine volume, accompanied by a marked reduction in maximal urinary osmolality compared with wild-type mice (800 $\mathrm{mOsm} / \mathrm{kg} \mathrm{H}_{2} \mathrm{O}$ versus $2,300 \mathrm{mOsm} / \mathrm{kg} \mathrm{H}_{2} \mathrm{O}$ in wild-type mice). As predicted, the concentration of urea in the inner medulla is reduced by more than threefold, which supports the proposed requirement for UTs in the IMCD for urea accumulation in the inner medullary interstitium.

Interestingly, UT-A1/3 deletion did not affect urine concentration in mice that were on a low-protein diet, indicating that the impaired urinary concentrating function in UT-A1/3 knockout mice depends on the excretion of large amounts of urea ${ }^{86}$ UT-A1 also seems to be more important than UT-A3 in urinary concentration, as the impaired urinary concentration in UT-A1/3 knockout mice was corrected by transgenic replacement of UT-A1 even without replacement of UT-A3. ${ }^{87}$

Unexpectedly, UT-A2 knockout mice do not manifest defective urinary concentration under normal conditions. ${ }^{88}$ However, these mice do show a mild decrease in maximal urine osmolality when on a low-protein diet $\left(2,500 \mathrm{mOsm} / \mathrm{kg} \mathrm{H}_{2} \mathrm{O}\right.$ versus $3,500 \mathrm{mOsm} / \mathrm{kg} \mathrm{H}_{2} \mathrm{O}$ in wild-type mice), with a $>1.5$-fold reduction in urea concentration in the inner medulla compared with wild-type mice. ${ }^{88}$ Intriguingly, double-knockout mice that lack UT-B and UT-A2 show lesser impairment in urinary concentration ability than do mice that lack only UT-B. ${ }^{85}$ One speculative explanation put forward for this unexpected observation is that deletion of UT-A2 reduces the loss of urea from the descending limb to the general circulation; however, the precise function of UT-A2 in the urinary concentrating mechanism remains unclear.

We note that interpretation of phenotype data from knockout mice is subject to the caveat that knockout mice generally manifest chronic altered expression of many proteins, as has been reported for UT knockout mice, ${ }^{89,90}$ so that findings can be the result of primary or secondary effects. Selective, rapidly acting UT inhibitors are useful in distinguishing between primary versus secondary effects.

\section{Lessons from humans with UT mutations}

The UT-B gene locus SLC14A1 determines an individual's Kidd blood group, and contains two alleles: $\mathrm{Jk}^{\mathrm{a}}$ and $\mathrm{Jk}^{\mathrm{b}}$. Rare individuals that lack both of these alleles, termed $\mathrm{Jk}_{\text {null }}$, show no clinical abnormality except for reduced maximal urinary concentration. Healthy adults concentrate their urine to $\sim 1,200 \mathrm{mOsm} / \mathrm{kg} \mathrm{H}_{2} \mathrm{O}$, whereas individuals with the $\mathrm{Jk}_{\text {null }}$ genotype concentrate urine to $\sim 800 \mathrm{mOsm} / \mathrm{kg} \mathrm{H}_{2} \mathrm{O} .{ }^{91,92} \mathrm{Jk}_{\text {null }}$ individuals manifest loss of UT-B function, demonstrated by the finding that their erythrocytes are resistant to lysis at high urea concentration. ${ }^{92}$ Humans with loss-of-function mutations in UT-A isoforms have not been identified.

Since 2011, gene association studies have identified single nucleotide polymorphisms (SNPs) of the SLC14A1 gene that show it to be a susceptibility locus for bladder carcinogenesis. ${ }^{93-95}$ An association between urinary bladder cancer and urine concentration 
or frequency of urination was proposed. Various human SNPs of UT-A2 have been linked to reduced diastolic blood pressure in Chinese men. ${ }^{96}$ Other UT-A2 SNPs have been associated with development of metabolic syndrome in Asians, ${ }^{97}$ although the responsible mechanisms and relevance of these observations are not clear.

\section{UT inhibitors}

Until recently, available UT inhibitors included the non-selective membrane-intercalating agent phloretin and chemical analogues of urea, such as dimethylthiourea (DMTU), that are effective at millimolar concentrations. ${ }^{4}$ The identification of selective, small-molecule UT inhibitors, some of which have an $\mathrm{IC}_{50}$ (concentration that causes 50\% inhibition) in the low nanomolar range, has arisen from the development of new assays of UT function that are suitable for high-throughput screening of diverse collections of drug-like molecules.

\section{Assaying UT function}

As the exclusive function of UT proteins is to facilitate the transport of urea (and some urea analogues), assaying UT function involves the measurement of urea transport from one side of a cell membrane, or an epithelium, to the other side (Figure 4). In one version of the assay, urea is added on one side of an epithelial cell layer, such as an epithelial cell culture grown on a porous filter, and its accumulation on the opposite side of the layer is measured by either an enzymatic, urease-based colorimetric assay, or by using radiolabelled ${ }^{14} \mathrm{C}$-urea (Figure 4a). This type of epithelial cell assay has been used to test UT inhibitors in UT-A1transfected MDCK cells. ${ }^{98}$ Measurement of transepithelial urea transport has been performed in isolated microperfused kidney tubules ${ }^{8}$ and other ex vivo epithelia such as toad bladder. ${ }^{99}$

Urea transport across individual cell membranes can be measured in large cells by assaying urea in extracellular fluid samples, which has been done in Xenopus oocytes. ${ }^{9}$ In smaller cells, urea transport is usually measured indirectly through the secondary effects of urea movement on water transport and hence on cell (or membrane vesicle or liposome) volume. This technique is used because urea equilibration occurs over seconds or tens of seconds, which makes the physical separation of cells from extracellular solution difficult.

Stopped-flow light scattering has been widely used to measure $\mathrm{P}_{\text {urea }}$ in erythrocytes. ${ }^{4,100} \mathrm{In}$ this method, erythrocytes in suspension are subjected to an inwardly directed urea gradient, which results in initial osmotic water efflux and cell shrinkage, detected as an increase in scattered light intensity, followed by urea and water influx and cell reswelling, detected as a phase of decreasing scattered light intensity (Figure $4 b$ ). Inhibition of the erythrocyte UT-B slows the reswelling phase. Other methods that follow cell volume kinetics have also been applied to measurement of urea transport, such as methods that use the volume-sensing fluorescent dye calcein. ${ }^{101}$ Although the methods described above provide accurate data on $\mathrm{P}_{\text {urea }}$, they are not easily adapted to automated high-throughput screening platforms.

The first high-throughput screening assay for the identification of UT inhibitors used erythrocytes, which natively express UT-B. ${ }^{98}$ The assay uses a read-out of erythrocyte lysis measured by near-infrared light absorbance at single time points (Figure 4c). Erythrocytes 
are preloaded with acetamide, a urea analogue that is transported by UT-B at a rate such that its equilibration time is similar to the equilibration time for osmotic water transport. This preloading imposes a large, outwardly directed gradient of acetamide that causes cell swelling, but this swelling is limited by UT-B-facilitated acetamide efflux. UT-B inhibition slows acetamide efflux, which leads to increased cell lysis. Once acetamide concentration was optimized for identification of UT-B inhibitors, the assay was found to be robust and sensitive, giving a statistical Z-factor of $\sim 0.6$, and to correlate well with UT-B inhibition data from stopped-flow light scattering measurements. As discussed below, the erythrocyte lysis assay has been used in several screening studies to identify UT-B inhibitors.

Development of a similar UT-A urea transport assay was challenging, because available cell lines do not natively express UT-A isoforms, UT-A-facilitated urea equilibration across cell membranes is rapid, and robust measurement of cell volume using an automated screening platform is difficult. One assay for UT-A1 inhibitors involves the measurement of cell volume changes that result from extracellular addition of urea to transfected MDCK cells that stably express UT-A1 (Figure 4d). ${ }^{102}$ Cell volume is measured indirectly using the fluorescence of the chloride-sensing, genetically encoded fluorescent protein YFP-H148QV163S; ${ }^{103}$ cell shrinkage increases cytoplasmic chloride concentration, which subsequently reduces YFP fluorescence. The MDCK cells are also transfected with the water channel aquaporin-1 to make osmotic water equilibration faster than urea equilibration. Addition of urea to the extracellular solution drives osmotic water efflux and cell shrinkage, which is followed by urea (and water) entry and a return to the original cell volume. The assay produces a robust difference between the fluorescence curve shapes with and without UTA1 inhibition, and correlates well with transepithelial urea transport measurements. This assay has been used in screening studies to identify UT-A1 inhibitors.

\section{Discovery of small-molecule UT inhibitors}

An initial screening of 50,000 drug-like small molecules that used the high-throughput erythrocyte lysis assay with human erythrocytes (Figure 4c) identified 30 UT-B inhibitors from the phenylsulphoxyoxozole, benzenesulphonanilide, phthalazinamine, and aminobenzimidazole chemical classes. ${ }^{98}$ Analysis of $~ 700$ chemical analogues of these four scaffolds identified many active compounds, the most potent of which inhibited human UT$\mathrm{B}$ urea transport with an $\mathrm{IC}_{50}$ of $\sim 10 \mathrm{nM}$ and caused $\sim 100 \%$ inhibition at concentrations over $1 \mu \mathrm{M}$. The compounds were characterized and used to confirm water transport through UT-B.

A subsequent screening of 100,000 compounds that used mouse erythrocytes aimed to identify potent inhibitors of rodent (and human) UT-B, because the inhibitors that were identified in the original screening of human UT-B urea transport had relatively weak activity against mouse and rat UT-B. ${ }^{104}$ The most potent UT-B inhibitor identified in this screening was the triazolothienopyrimidine 3-(4-ethyl-benzenesulphonyl)-thieno[2,3-e] $[1,2,3]$ triazolo[1,5-a]pyrimidin-5-yl]-thiophen-2-ylmethylamine $\left(\mathrm{UTB}_{\text {inh }^{-14}}\right.$; Figure 5). $\mathrm{UTB}_{\text {inh }}-14$, which was synthesized and purified in five steps, fully and reversibly inhibited urea transport with an $\mathrm{IC}_{50}$ of $10 \mathrm{nM}$ for human UT-B (Figure $5 \mathrm{~b}$ ) and $25 \mathrm{nM}$ for mouse UT-B. ${ }^{104}$ UTB $_{\text {inh }}-14$ is highly selective, with no inhibition of UT-A1 even at high 
concentration. Competition studies showed reduced potency of inhibition with increased urea concentration, which suggests that $\mathrm{UTB}_{\text {inh }^{-}} 14$ binds to the UT-B protein near the urea binding site of $\mathrm{UTB}_{\text {inh-14 }}-14$ in a cleft near the cytoplasmic pore region of the UT-B molecule (Figure 5c). As described below, $\mathrm{UTB}_{\text {inh }^{-1}} 14$ has been used in mice to test the effect of acute UT-B inhibition on urinary concentrating function.

Medicinal chemistry has been used to optimize triazolothienopyrimidine properties and increase the metabolic stability of $\mathrm{UTB}_{\text {inh }}-14 .{ }^{105}$ Analysis of structure-activity relationships indicated that $\mathrm{CH}_{2}$ hydroxylation of the ethyl substituent in $\mathrm{UTB}_{\text {inh }}-14$ is a major determinant of the molecule's metabolic stability. Replacement of the $\mathrm{CH}_{2}$ hydrogen atoms with fluorine atoms to produce the compound \{3-[4-(1,1-difluoroethyl)-benzenesulphonyl]thieno[2,3-e][1,2,3]triazolo[1,5-a] pyrimidin-5-yl $\}$-thiophen-2-ylmethylamine resulted in a 40-fold improvement of in vitro metabolic stability over $\mathrm{UTB}_{\text {inh }}-14$ with little effect on UT-B inhibition potency. The optimized UT-B inhibitor accumulated in the kidneys and urine in mice, and reduced maximum urinary concentration.

High-throughput screening has also identified small molecules that inhibit UT-A proteins (Figure 6). Screening of 100,000 synthetic small molecules for UT-A1 inhibition using the assay described in MDCK cells (Figure 4d) identified four classes of compounds, each with a low-micromolar $\mathrm{IC}_{50}$; the most potent of these compounds was $\mathrm{UTA}_{\text {inh }}$-A1 (Figure 6a). ${ }^{102}$ The UT-A1 isoform was used for the screening because it is predicted to be the most important isoform for urinary concentration. UT-A1 inhibition by each of the UT-A1 inhibitors was reversible and largely non-competitive. An interesting finding was the identification of compounds that have a wide range of selectivities for UT-A1 and UT-B; even within the same chemical class, relatively minor chemical modifications produced compounds with very high selectivity and others with little UT-A1 versus UT-B selectivity.

Subsequent screening was performed to identify UT-A1-selective inhibitors that have suitable pharmacological properties for efficacy testing in rodents. ${ }^{106}$ This screening identified one compound - the arylthiazole $\mathrm{UTA}_{\text {inh }}$-E02 (Figure 6a) — that reversibly inhibited UT-A1 urea transport with an $\mathrm{IC}_{50}$ of $1-2 \mu \mathrm{M}$ via a non-competitive mechanism, and that has $~ 100$-fold greater selectivity for UT-A1 than for UT-B (Figure 6b). Liquid chromatography-mass spectrometry was used to predict therapeutic inhibitor concentrations in rats following intravenous bolus administration.

Interestingly, screening of approved and investigational drugs and natural products also identified nicotine, sanguinarine and an indolcarbonylchromenone as UT-A1 inhibitors, albeit with relatively weak $\mathrm{IC}_{50}$ values of $10-20 \mu \mathrm{M} .{ }^{107}$

\section{Diuretic action of UT inhibitors in rodents}

The UT-B-selective inhibitor $\mathrm{UTB}_{\text {inh-1 }}-14$ was studied in mice after pharmacological studies had been used to establish the optimal compound administration vehicle, dose, route and timing to maintain concentrations in the kidneys and urine that are predicted to be therapeutic. ${ }^{104}$ Mice were administered intraperitoneal $\mathrm{UTB}_{\text {inh }}$-14 or a vehicle control, followed by the vasopressin receptor agonist dDAVP. Urine osmolality was mildly reduced in $\mathrm{UTB}_{\text {inh }^{-1}}$ 14-treated mice compared with vehicle-treated mice; this reduced osmolality was 
similar to the urine osmolality observed in UT-B knock-out mice, in which UTB $_{\text {inh }}$-14 had no significant effect (Figure 7a). $\mathrm{UTB}_{\text {inh }^{-1}} 14$ also mildly increased urine output and reduced urine osmolality in mice that were given free access to water. The fact that the diuretic effect of selective UT-B inhibition was relatively minor was not unexpected, as tubule epithelial UT-A is predicted to be the major target for diuretic effect. A subsequent study of a nonselective UT inhibitor in rats also reported diuretic action. ${ }^{108}$ Acute inhibition of UT-B by selective inhibitors should be useful in studying the potential extrarenal effects of UT-B inhibition, as mentioned above.

The effect of the UT-A1-selective inhibitor $\mathrm{UTA}_{\text {inh }}$-E02 on urinary concentration has been studied by intraperitoneal injection of $\mathrm{UTA}_{\text {inh }}$-E02 into rats that were also administered dDAVP. ${ }^{106}$ In vehicle-treated animals, dDAVP reduced urine volume and increased urine osmolality, but $\mathrm{UTA}_{\text {inh }}$-E02 prevented these changes. At 3-6 $\mathrm{h}$ after $\mathrm{UTA}_{\mathrm{inh}}-\mathrm{E} 02$ administration, little residual difference remained between $\mathrm{UTA}_{\text {inh }}$-E02-treated and vehicletreated rats, indicating inhibitor reversibility (Figure $7 \mathrm{~b}$ ). In hydrated rats, increased urine volume and reduced urine osmolality were seen at $0-3 \mathrm{~h}$ after $\mathrm{UTA}_{\text {inh }}$-E02 administration; urine volume and osmolality returned to baseline in the 3-6 $\mathrm{h}$ collection. These studies support the hypothesis that selective UT-A inhibition has a diuretic effect; this effect is advantageous for drug development because UT-A isoforms are primarily expressed in kidney, whereas UT-B is relatively ubiquitous, so off-target effects are likely to be less problematic with UT-A inhibition than with UT-B inhibition.

A 2012 study examined the diuretic action of the non-selective UT inhibitor DMTU, which is a urea analogue that has been used at high doses in experimental animal models as a hydroxyl radical scavenger, where it inhibited urinary concentration. ${ }^{109}$ DMTU fully and reversibly inhibited rat UT-A1 and UT-B by a non-competitive mechanism with an $\mathrm{IC}_{50}$ of 2-3 mM. ${ }^{107}$ Following a single intraperitoneal injection of $500 \mathrm{mg} / \mathrm{kg}$ DMTU, peak plasma concentration of DMTU was $9 \mathrm{mM}$ with a half-life of $\sim 10 \mathrm{~h}$, and urine concentration of DMTU was $20-40 \mathrm{mM}$. Chronic treatment with high-dose DMTU resulted in a sustained reduction in urine osmolality from $1,800 \mathrm{mOsm} / \mathrm{kg} \mathrm{H}_{2} \mathrm{O}$ to $600 \mathrm{mOsm} / \mathrm{kg} \mathrm{H}_{2} \mathrm{O}$ and a threefold increase in urine output, both of which fully reversed after DMTU discontinuation. DMTU did not further impair the already reduced urinary concentrating function in rats on a low-protein diet. Rats that were given chronic DMTU treatment showed mild hypokalaemia, but no abnormalities in serum chemistry. Hypokalaemia is usually seen after diuretic administration, and its likely cause in the DMTU-treated rats is, at least in part, an increased distal delivery of urinary fluid. Short-term DMTU administration indicated a salt-sparing diuretic action. The DMTU data further support the diuretic efficacy of UT inhibition.

\section{Indications for UT inhibitors}

UT inhibitors, particularly inhibitors of UT-A1, have several potential clinical indications. UT-blocking diuretics may be useful, either alone or in combination with conventional diuretics that block salt transport, in oedema caused by fluid overload (congestive heart failure, nephrotic syndrome and cirrhosis) and in hyponatraemia caused by chronic elevation in vasopressin level (syndrome of inappropriate antidiuretic hormone secretion [SIADH]). Their unique mechanism of action on renal countercurrent mechanisms means that UT-A1 
inhibitors might be effective in refractory oedema, for which conventional diuretics such as furosemide and thiazides have limited effectiveness, and could produce a relatively saltsparing diuresis. After optimization of their pharmacological properties, testing of UT-A1 inhibitors in clinically relevant animal models of oedema and hyponatraemia will be important to define their clinical indications.

\section{Conclusions}

Our understanding of urea transport mechanisms and the role of urea transport in the urinary concentrating mechanism has been greatly advanced by the identification of UTs and studies in transgenic mice and rodents treated with UT inhibitors. However, unresolved issues remain concerning UT physiology and the translation of UT biology into therapeutics. The precise roles and regulation of the different mammalian UT isoforms in the urinary concentrating mechanism remain incompletely understood, as does the validity of translating findings in animal models to humans. Nevertheless, the available results provide a compelling rationale for advancing UT inhibitors, particularly inhibitors of UT-A1, as saltsparing diuretics with a mechanism of action that differs from that of existing salt-blocking diuretics. Target properties of UT inhibitors for clinical applications include high UT-A1 inhibition potency and selectivity, good pharmacological properties such as oral bioavailability, and few off-target effects. Ultimately, clinical trials will be needed to assess the efficacy and safety of UT inhibitors alone and together with conventional diuretics, the occurrence of hypokalaemia with UT use, and the clinical indication profile of UTs.

\section{Acknowledgments}

M.O.A. and A.S.V. are funded by the National Institutes of Health, and A.S.V. is also funded by the Guthy-Jackson Charitable Foundation and the Cystic Fibrosis Foundation.

\section{References}

1. Gamble JL, McKhann CF, Butler AM, Tuthill E. An economy of water in renal function referable to urea. Am J Physiol. 1934; 109:139-154.

2. Aukland K. Renal tubular permeability to urea with special reference to accumulation of urea in the renal medulla. Scand J Clin Lab Invest. 1961; 13:646-660. [PubMed: 13863278]

3. Magnan De Bornier B. Effect of urea on the permeability of the erythrocyte membrane [French]. Montp Med. 1958; 53:181-184. [PubMed: 13552637]

4. Mayrand RR, Levitt DG. Urea and ethylene glycol-facilitated transport systems in the human red cell membrane. Saturation, competition, and asymmetry. J Gen Physiol. 1983; 81:221-237. [PubMed: 6842173]

5. Gallucci E, Micelli S, Lippe C. Non-electrolyte permeability across thin lipid membranes. Arch Int Physiol Biochim. 1971; 79:881-887. [PubMed: 4112719]

6. Macey RI. Transport of water and urea in red blood cells. Am J Physiol. 1984; 246:C195-C203. [PubMed: 6199982]

7. Schafer JA, Troutman SL, Andreoli TE. Osmosis in cortical collecting tubules. ADH-independent osmotic flow rectification. J Gen Physiol. 1974; 64:228-240. [PubMed: 4846768]

8. Sands JM, Knepper MA. Urea permeability of mammalian inner medullary collecting duct system and papillary surface epithelium. J Clin Invest. 1987; 79:138-147. [PubMed: 3793921]

9. Zhang RB, Verkman AS. Water and urea permeability properties of Xenopus oocytes: expression of mRNA from toad urinary bladder. Am J Physiol. 1991; 260:C26-C34. [PubMed: 1987778] 
10. You G, et al. Cloning and characterization of the vasopressin-regulated urea transporter. Nature. 1993; 365:844-847. [PubMed: 8413669]

11. Fenton RA, Hewitt JE, Howorth A, Cottingham CA, Smith CP. The murine urea transporter genes Slc14al and Slc14a2 occur in tandem on chromosome 18. Cytogenet Cell Genet. 1999; 87:95-96. [PubMed: 10640821]

12. Olives B, et al. Cloning and functional expression of a urea transporter from human bone marrow cells. J Biol Chem. 1994; 269:31649-31652. [PubMed: 7989337]

13. Shayakul C, Clémençon B, Hediger MA. The urea transporter family (SLC14): physiological, pathological and structural aspects. Mol Aspects Med. 2013; 34:313-322. [PubMed: 23506873]

14. Tickle P, Thistlethwaite A, Smith CP, Stewart GS. Novel bUT-B2 urea transporter isoform is constitutively activated. Am J Physiol Regul Integr Comp Physiol. 2009; 297:R323-R329. [PubMed: 19474392]

15. Stewart GS, et al. UT-B is expressed in bovine rumen: potential role in ruminal urea transport. Am J Physiol Regul Integr Comp Physiol. 2005; 289:R605-R612. [PubMed: 15845882]

16. Nakayama Y, Peng T, Sands JM, Bagnasco SM. The TonE/TonEBP pathway mediates tonicityresponsive regulation of UT-A urea transporter expression. J Biol Chem. 2000; 275:38275-38280. [PubMed: 10995747]

17. Nakayama Y, et al. Cloning of the rat Slc14a2 gene and genomic organization of the UT-A urea transporter. Biochim Biophys Acta. 2001; 1518:19-26. [PubMed: 11267655]

18. Fenton RA, et al. Structure and characterization of the mouse UT-A gene (Slc14a2). Am J Physiol Renal Physiol. 2002; 282:F630-F638. [PubMed: 11880324]

19. Fenton RA, et al. Molecular characterization of a novel UT-A urea transporter isoform (UT-A5) in testis. Am J Physiol Cell Physiol. 2000; 279:C1425-C1431. [PubMed: 11029290]

20. Smith CP. Mammalian urea transporters. Exp Physiol. 2009; 94:180-185. [PubMed: 19028811]

21. Smith CP, Potter EA, Fenton RA, Stewart GS. Characterization of a human colonic cDNA encoding a structurally novel urea transporter, hUT-A6. Am J Physiol Cell Physiol. 2004; 287:C1087-C1093. [PubMed: 15189812]

22. Karakashian A, et al. Cloning and characterization of two new isoforms of the rat kidney urea transporter: UT-A3 and UT-A4. J Am Soc Nephrol. 1999; 10:230-237. [PubMed: 10215321]

23. Smith CP, Fenton RA. Genomic organization of the mammalian SLC14a2 urea transporter genes. J Membr Biol. 2006; 212:109-117. [PubMed: 17264986]

24. Bankir LT, Trinh-Trang-Tan MM. Renal urea transporters. Direct and indirect regulation by vasopressin. Exp Physiol. 2000; 85:243S-252S. [PubMed: 10795928]

25. Levin EJ, Quick M, Zhou M. Crystal structure of a bacterial homologue of the kidney urea transporter. Nature. 2009; 462:757-761. [PubMed: 19865084]

26. Levin EJ, et al. Structure and permeation mechanism of a mammalian urea transporter. Proc Natl Acad Sci USA. 2012; 109:11194-11199. [PubMed: 22733730]

27. Bradford AD, et al. 97- and 117-kDa forms of collecting duct urea transporter UT-A1 are due to different states of glycosylation. Am J Physiol Renal Physiol. 2001; 281:F133-F143. [PubMed: 11399654]

28. Blount MA, Klein JD, Martin CF, Tchapyjnikov D, Sands JM. Forskolin stimulates phosphorylation and membrane accumulation of UT-A3. Am J Physiol Renal Physiol. 2007; 293:F1308-F1313. [PubMed: 17686955]

29. Minocha R, Studley K, Saier MH Jr. The urea transporter (UT) family: bioinformatic analyses leading to structural, functional, and evolutionary predictions. Receptors Channels. 2003; 9:345352. [PubMed: 14698962]

30. von Heijne G, Gavel Y. Topogenic signals in integral membrane proteins. Eur J Biochem. 1988; 174:671-678. [PubMed: 3134198]

31. Lucien N, et al. Antigenic and functional properties of the human red blood cell urea transporter hUT-B1. J Biol Chem. 2002; 277:34101-34108. [PubMed: 12093813]

32. Shayakul C, Hediger MA. The SLC14 gene family of urea transporters. Pflugers Arch. 2004; 447:603-609. [PubMed: 12856182] 
33. Azouzi S, et al. Energetic and molecular water permeation mechanisms of the human red blood cell urea transporter B. PLoS One. 2013; 8:e82338. [PubMed: 24376529]

34. Yang B, Verkman AS. Urea transporter UT3 functions as an efficient water channel. Direct evidence for a common water/urea pathway. J Biol Chem. 1998; 273:9369-9372. [PubMed: 9545259]

35. Yang B, Verkman AS. Analysis of double knockout mice lacking aquaporin-1 and urea transporter UT-B. Evidence for UT-B-facilitated water transport in erythrocytes. J Biol Chem. 2002; 277:36782-36786. [PubMed: 12133842]

36. Zhao D, Sonawane ND, Levin MH, Yang B. Comparative transport efficiencies of urea analogues through urea transporter UT-B. Biochim Biophys Acta. 2007; 1768:1815-1821. [PubMed: 17506977]

37. Stewart GS, et al. The basolateral expression of mUT-A3 in the mouse kidney. Am J Physiol Renal Physiol. 2004; 286:F979-F987. [PubMed: 15075194]

38. Terris JM, Knepper MA, Wade JB. UT-A3: localization and characterization of an additional urea transporter isoform in the IMCD. Am J Physiol Renal Physiol. 2001; 280:F325-F332. [PubMed: 11208608]

39. Blessing NW, Blount MA, Sands JM, Martin CF, Klein JD. Urea transporters UT-A1 and UT-A3 accumulate in the plasma membrane in response to increased hypertonicity. Am J Physiol Renal Physiol. 2008; 295:F1336-F1341. [PubMed: 18715940]

40. Wade JB, et al. UT-A2: a 55-kDa urea transporter in thin descending limb whose abundance is regulated by vasopressin. Am J Physiol Renal Physiol. 2000; 278:F52-F62. [PubMed: 10644655]

41. Timmer RT, et al. Localization of the urea transporter UT-B protein in human and rat erythrocytes and tissues. Am J Physiol Cell Physiol. 2001; 281:C1318-C1325. [PubMed: 11546670]

42. Xu Y, et al. Endothelial cells of the kidney vasa recta express the urea transporter HUT11. Kidney Int. 1997; 51:138-146. [PubMed: 8995727]

43. Doran JJ, et al. Tissue distribution of UT-A and UT-B mRNA and protein in rat. Am J Physiol Regul Integr Comp Physiol. 2006; 290:R1446-R1459. [PubMed: 16373440]

44. Collins D, et al. Differential protein abundance and function of UT-B urea transporters in human colon. Am J Physiol Gastrointest Liver Physiol. 2010; 298:G345-G351. [PubMed: 19926813]

45. Inoue $\mathrm{H}$, et al. Identification and characterization of a Kidd antigen/UT-B urea transporter expressed in human colon. Am J Physiol Cell Physiol. 2004; 287:C30-C35. [PubMed: 14985236]

46. Wagner L, Klein JD, Sands JM, Baylis C. Urea transporters are distributed in endothelial cells and mediate inhibition of L-arginine transport. Am J Physiol Renal Physiol. 2002; 283:F578-F582. [PubMed: 12167610]

47. Tsukaguchi $\mathrm{H}$, et al. Cloning and characterization of the urea transporter UT3: localization in rat kidney and testis. J Clin Invest. 1997; 99:1506-1515. [PubMed: 9119994]

48. Kwun YS, et al. Immunohistochemical localization of urea transporters A and B in the rat cochlea. Hear Res. 2003; 183:84-96. [PubMed: 13679141]

49. Duchesne R, et al. UT-A urea transporter protein in heart: increased abundance during uremia, hypertension, and heart failure. Circ Res. 2001; 89:139-145. [PubMed: 11463720]

50. Fenton RA, Cooper GJ, Morris ID, Smith CP. Coordinated expression of UT-A and UT-B urea transporters in rat testis. Am J Physiol Cell Physiol. 2002; 282:C1492-C1501. [PubMed: 11997264]

51. Klein JD, Timmer RT, Rouillard P, Bailey JL, Sands JM. UT-A urea transporter protein expressed in liver: upregulation by uremia. J Am Soc Nephrol. 1999; 10:2076-2083. [PubMed: 10505683]

52. Sands JM. Mammalian urea transporters. Annu Rev Physiol. 2003; 65:543-566. [PubMed: 12524463]

53. Li X, et al. Mice lacking urea transporter UT-B display depression-like behavior. J Mol Neurosci. 2012; 46:362-372. [PubMed: 21750947]

54. Meng Y, et al. Surface electrocardiogram and action potential in mice lacking urea transporter UTB. Sci China C Life Sci. 2009; 52:474-478. [PubMed: 19471871]

55. Yu H, et al. Differential protein expression in heart in UT-B null mice with cardiac conduction defects. Proteomics. 2009; 9:504-511. [PubMed: 19132680] 
56. Dong Z, et al. Urea transporter UT-B deletion induces DNA damage and apoptosis in mouse bladder urothelium. PLoS ONE. 2013; 8:e76952. [PubMed: 24204711]

57. Guo L, et al. Reduced urea flux across the blood-testis barrier and early maturation in the male reproductive system in UT-B-null mice. Am J Physiol Cell Physiol. 2007; 293:C305-C312. [PubMed: 17475664]

58. Reif MC, Troutman SL, Schafer JA. Sustained response to vasopressin in isolated rat cortical collecting tubule. Kidney Int. 1984; 26:725-732. [PubMed: 6097738]

59. Rocha AS, Kudo LH. Water, urea, sodium, chloride, and potassium transport in the in vitro isolated perfused papillary collecting duct. Kidney Int. 1982; 22:485-491. [PubMed: 6759756]

60. Wall SM, Han JS, Chou CL, Knepper MA. Kinetics of urea and water permeability activation by vasopressin in rat terminal IMCD. Am J Physiol. 1992; 262:F989-F998. [PubMed: 1320335]

61. Chen G, Fröhlich O, Yang Y, Klein JD, Sands JM. Loss of N-linked glycosylation reduces urea transporter UT-A1 response to vasopressin. J Biol Chem. 2006; 281:27436-27442. [PubMed: 16849333]

62. Klein JD, et al. Vasopressin increases plasma membrane accumulation of urea transporter UT-A1 in rat inner medullary collecting ducts. J Am Soc Nephrol. 2006; 17:2680-2686. [PubMed: 16959825]

63. Zhang C, Sands JM, Klein JD. Vasopressin rapidly increases phosphorylation of UT-A1 urea transporter in rat IMCDs through PKA. Am J Physiol Renal Physiol. 2002; 282:F85-F90. [PubMed: 11739116]

64. Blount MA, et al. Phosphorylation of UT-A1 urea transporter at serines 486 and 499 is important for vasopressin-regulated activity and membrane accumulation. Am J Physiol Renal Physiol. 2008; 295:F295-F299. [PubMed: 18495802]

65. Fenton RA. Essential role of vasopressin-regulated urea transport processes in the mammalian kidney. Pflugers Arch. 2009; 458:169-177. [PubMed: 19011892]

66. Hwang S, et al. Vasopressin increases phosphorylation of Ser84 and Ser486 in Slc14a2 collecting duct urea transporters. Am J Physiol Renal Physiol. 2010; 299:F559-F567. [PubMed: 20576681]

67. Wang Y, Klein JD, Liedtke CM, Sands JM. Protein kinase C regulates urea permeability in the rat inner medullary collecting duct. Am J Physiol Renal Physiol. 2010; 299:F1401-F1406. [PubMed: 20861079]

68. Wang Y, Klein JD, Froehlich O, Sands JM. Role of protein kinase C-a in hypertonicity-stimulated urea permeability in mouse inner medullary collecting ducts. Am J Physiol Renal Physiol. 2013; 304:F233-F238. [PubMed: 23097465]

69. Chen G. New advances in urea transporter UT-A1 membrane trafficking. Int J Mol Sci. 2013; 14:10674-10682. [PubMed: 23698785]

70. Su H, Chen M, Sands JM, Chen G. Activation of the cAMP/PKA pathway induces UT-A1 urea transporter monoubiquitination and targets it for lysosomal degradation. Am J Physiol Renal Physiol. 2013; 305:F1775-F1782. [PubMed: 24133116]

71. Sachs G, Kraut JA, Wen Y, Feng J, Scott DR. Urea transport in bacteria: acid acclimation by gastric Helicobacter spp. J Membr Biol. 2006; 212:71-82. [PubMed: 17264989]

72. Sebbane F, et al. The Yersinia pseudotuberculosis Yut protein, a new type of urea transporter homologous to eukaryotic channels and functionally interchangeable in vitro with the Helicobacter pylori UreI protein. Mol Microbiol. 2002; 45:1165-1174. [PubMed: 12180933]

73. Gray LR, Gu SX, Quick M, Khademi S. Transport kinetics and selectivity of $H p$ UreI, the urea channel from Helicobacter pylori. Biochemistry. 2011; 50:8656-8663. [PubMed: 21877689]

74. Liu LH, Ludewig U, Gassert B, Frommer WB, von Wirén N. Urea transport by nitrogen-regulated tonoplast intrinsic proteins in Arabidopsis. Plant Physiol. 2003; 133:1220-1228. [PubMed: 14576283]

75. Liu LH, Ludewig U, Frommer WB, von Wirén N. AtDUR3 encodes a new type of high-affinity urea/ $\mathrm{H}^{+}$symporter in Arabidopsis. Plant Cell. 2003; 15:790-800. [PubMed: 12615950]

76. McDonald MD, Smith CP, Walsh PJ. The physiology and evolution of urea transport in fishes. J Membr Biol. 2006; 212:93-107. [PubMed: 17264987]

77. Weihrauch D, Wilkie MP, Walsh PJ. Ammonia and urea transporters in gills of fish and aquatic crustaceans. J Exp Biol. 2009; 212:1716-1730. [PubMed: 19448081] 
78. Hediger MA, et al. Structure, regulation and physiological roles of urea transporters. Kidney Int. 1996; 49:1615-1623. [PubMed: 8743465]

79. Mistry AC, et al. A novel type of urea transporter, UT-C, is highly expressed in proximal tubule of seawater eel kidney. Am J Physiol Renal Physiol. 2005; 288:F455-F465. [PubMed: 15383403]

80. Pannabecker TL. Comparative physiology and architecture associated with the mammalian urine concentrating mechanism: role of inner medullary water and urea transport pathways in the rodent medulla. Am J Physiol Regul Integr Comp Physiol. 2013; 304:R488-R503. [PubMed: 23364530]

81. Sands JM. Critical role of urea in the urine-concentrating mechanism. J Am Soc Nephrol. 2007; 18:670-671. [PubMed: 17251382]

82. Sands JM, Layton HE. The physiology of urinary concentration: an update. Semin Nephrol. 2009; 29:178-195. [PubMed: 19523568]

83. Sands JM, Layton HE. Advances in understanding the urine-concentrating mechanism. Annu Rev Physiol. 2014; 76:387-409. [PubMed: 24245944]

84. Yang B, Bankir L, Gillespie A, Epstein CJ, Verkman AS. Urea-selective concentrating defect in transgenic mice lacking urea transporter UT-B. J Biol Chem. 2002; 277:10633-10637. [PubMed: 11792714]

85. Lei $\mathrm{T}$, et al. Role of thin descending limb urea transport in renal urea handling and the urine concentrating mechanism. Am J Physiol Renal Physiol. 2011; 301:F1251-F1259. [PubMed: 21849488]

86. Fenton RA, Chou CL, Stewart GS, Smith CP, Knepper MA. Urinary concentrating defect in mice with selective deletion of phloretin-sensitive urea transporters in the renal collecting duct. Proc Natl Acad Sci USA. 2004; 101:7469-7474. [PubMed: 15123796]

87. Klein JD, et al. Transgenic mice expressing UT-A1, but lacking UT-A3, have intact urine concentrating ability. FASEB J. 2013; 27:1111.17. Meeting Abstract Suppl.

88. Uchida $S$, et al. Impaired urea accumulation in the inner medulla of mice lacking the urea transporter UT-A2. Mol Cell Biol. 2005; 25:7357-7363. [PubMed: 16055743]

89. Klein JD, Sands JM, Qian L, Wang X, Yang B. Upregulation of urea transporter UT-A2 and water channels AQP2 and AQP3 in mice lacking urea transporter UT-B. J Am Soc Nephrol. 2004; 15:1161-1167. [PubMed: 15100356]

90. Fenton RA, et al. Renal phenotype of UT-A urea transporter knockout mice. J Am Soc Nephrol. 2005; 16:1583-1592. [PubMed: 15829709]

91. Lucien N, et al. Characterization of the gene encoding the human Kidd blood group/urea transporter protein. Evidence for splice site mutations in $\mathrm{Jk}_{\text {null }}$ individuals. J Biol Chem. 1998; 273:12973-12980. [PubMed: 9582331]

92. Sands JM, Gargus JJ, Fröhlich O, Gunn RB, Kokko JP. Urinary concentrating ability in patients with Jk(a-b-) blood type who lack carrier-mediated urea transport. J Am Soc Nephrol. 1992; 2:1689-1696. [PubMed: 1498276]

93. Garcia-Closas M, et al. A genome-wide association study of bladder cancer identifies a new susceptibility locus within SLC14A1, a urea transporter gene on chromosome 18q12.3. Hum Mol Genet. 2011; 20:4282-4289. [PubMed: 21824976]

94. Koutros S, et al. Genetic susceptibility loci, pesticide exposure and prostate cancer risk. PLoS ONE. 2013; 8:e58195. [PubMed: 23593118]

95. Rafnar T, et al. European genome-wide association study identifies $S L C 14 A 1$ as a new urinary bladder cancer susceptibility gene. Hum Mol Genet. 2011; 20:4268-4281. [PubMed: 21750109]

96. Ranade K, et al. Genetic variation in the human urea transporter-2 is associated with variation in blood pressure. Hum Mol Genet. 2001; 10:2157-2164. [PubMed: 11590132]

97. Tsai HJ, et al. Genetic variants of human urea transporter-2 are associated with metabolic syndrome in Asian population. Clin Chim Acta. 2010; 411:2009-2013. [PubMed: 20797394]

98. Levin MH, de la Fuente R, Verkman AS. Urearetics: a small molecule screen yields nanomolar potency inhibitors of urea transporter UT-B. FASEB J. 2007; 21:551-563. [PubMed: 17202246]

99. Shpun S, Katz U. Urea transport across urinary bladder and salt acclimation in toad (Bufo viridis). Am J Physiol. 1990; 258:R883-R888. [PubMed: 2331031] 
100. Levitt DG, Mlekoday HJ. Reflection coefficient and permeability of urea and ethylene glycol in the human red cell membrane. J Gen Physiol. 1983; 81:239-253. [PubMed: 6842174]

101. Verkman AS, Anderson MO, Papadopoulos MC. Aquaporins: important but elusive drug targets. Nat Rev Drug Discov. 2014; 13:259-277. [PubMed: 24625825]

102. Esteva-Font C, Phuan PW, Anderson MO, Verkman AS. A small molecule screen identifies selective inhibitors of urea transporter UT-A. Chem Biol. 2013; 20:1235-1244. [PubMed: 24055006]

103. Baumgart F, Rossi A, Verkman AS. Light inactivation of water transport and protein-protein interactions of aquaporin-Killer Red chimeras. J Gen Physiol. 2012; 139:83-91. [PubMed: 22200949]

104. Yao C, et al. Triazolothienopyrimidine inhibitors of urea transporter UT-B reduce urine concentration. J Am Soc Nephrol. 2012; 23:1210-1220. [PubMed: 22491419]

105. Anderson MO, et al. Nanomolar potency and metabolically stable inhibitors of kidney urea transporter UT-B. J Med Chem. 2012; 55:5942-5950. [PubMed: 22694147]

106. Esteva-Font C, et al. Diuresis and reduced urinary osmolality in rats produced by small-molecule UT-A-selective urea transport inhibitors. FASEB J. 2014; 28:3878-3890. [PubMed: 24843071]

107. Esteva-Font C, et al. Nanomolar-potency, UT-A-selective inhibitors of kidney tubule urea transporters produce salt-sparing diuresis in rats. American Society of Nephrology abstract. in press.

108. Li F, et al. A novel small-molecule thienoquinolin urea transporter inhibitor acts as a potential diuretic. Kidney Int. 2013; 83:1076-1086. [PubMed: 23486518]

109. Cil O, Ertunc M, Onur R. The diuretic effect of urea analog dimethylthiourea in female Wistar rats. Hum Exp Toxicol. 2012; 31:1050-1055. [PubMed: 23023029] 


\section{Key points}

- Urea transporter (UT) proteins facilitate the passive transport of urea driven by a concentration gradient across the cell plasma membrane in some kidney and extrarenal cells

- The kidney expresses UT-A1 and UT-A3 in inner medullary collecting duct epithelium, UT-A2 in thin descending limbs of the loop of Henle, and UT-B in descending vasa recta endothelium

- Kidney UTs are required for the generation of concentrated urine

- High-throughput screening has identified potent and selective small-molecule inhibitors of UT-A and UT-B that produce a salt-sparing diuresis in rodent models

- UT inhibitors may be useful alone or in combination with conventional diuretics for therapy of various oedemas and hyponatraemias 


\section{Review criteria}

We searched PubMed (all years) using the search terms "urea transport", "renal concentrating mechanism" and "urea transporter knockout". All articles identified were full-text papers. We also read abstracts from the American Society of Nephrology and Experimental Biology meetings (2011-2014) to identify further relevant studies. 
UT-A1

(N)
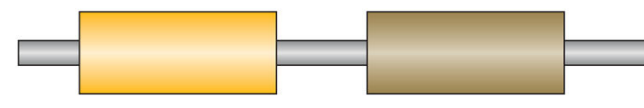

UT-A2

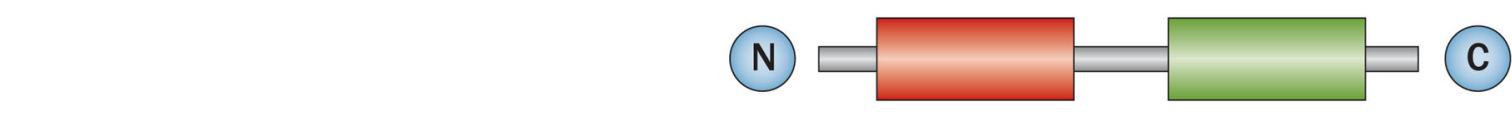

UT-A3

(N)

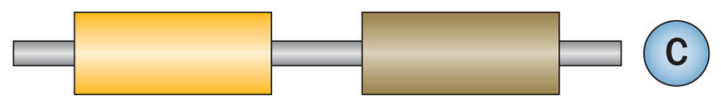

UT-A4

(N)

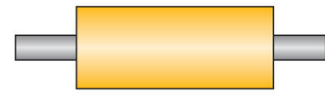

UT-A5

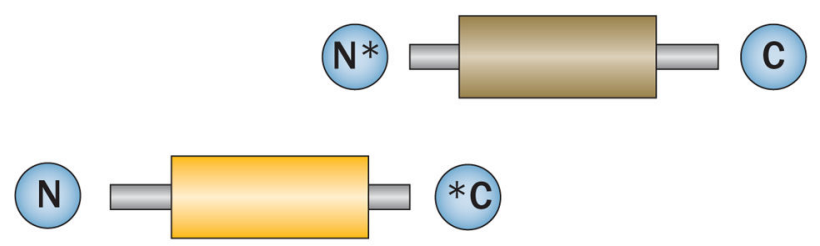

UT-A6

Figure 1.

Schematic representation of the primary structures of mammalian UT-A isoforms. UT-A1 comprises four hydrophobic regions. UT-A2, UT-A3 and UT-A4 each comprise two hydrophobic regions, which are identical to regions in UT-A1, as indicated by matching coloured boxes. UT-A5 and UT-A6 are identical to UT-A3 except for a unique N-terminus in UT-A5 and a unique C-terminus in UT-A6. Coloured boxes represent hydrophobic regions, grey lines represent regions with common DNA coding sequences, the dashed black line connects regions that are continuous with one another, asterisks represent regions that have unique coding sequences. Abbreviation: UT, urea transporter. Permission obtained from Wiley @ Smith, C. P. Mammalian urea transporters. Exp. Physiol. 94, 180-185 (2009). 


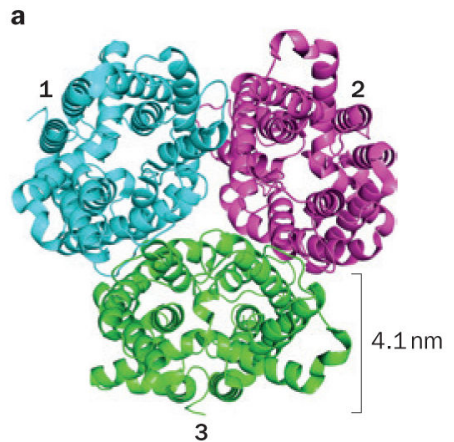

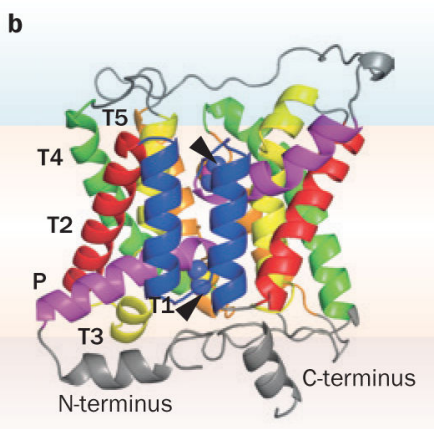

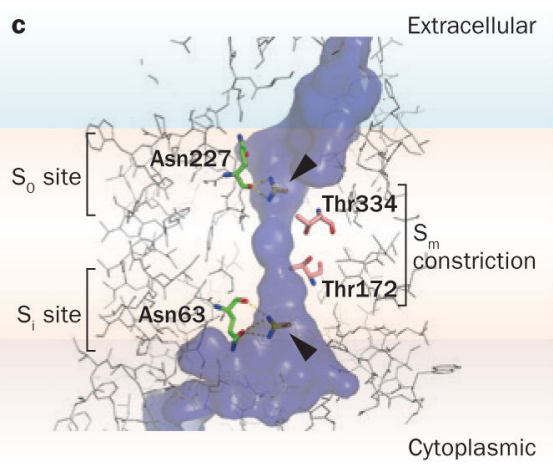

Figure 2.

Molecular structure of bovine UT-B. a | Top view of the extracellular face of the bovine UTB homotrimer. Monomers are labelled 1-3. Based on the X-ray crystal structure data (Protein Data Bank ID 4EZD). ${ }^{26} \mathbf{b} \mid$ Structure of a bovine UT-B monomer viewed from its side, with the position of the membrane approximated, and with two co-crystallized selenourea molecules indicated in spherical form at the putative urea binding sites (arrowheads). c| Magnified view of a UT-B monomer and narrow channel surface. The cocrystallized selenourea molecules (arrowheads) are depicted interacting through hydrogen bonds with Asn227 at the $S_{0}$ site and Asn63 at the $S_{i}$ site. Thr334 and Thr172 form the narrow $\mathrm{S}_{\mathrm{m}}$ constriction at the centre of the channel. Abbreviations: $\mathrm{P}$, tilted helix; $\mathrm{T}$, transmembrane helix. 


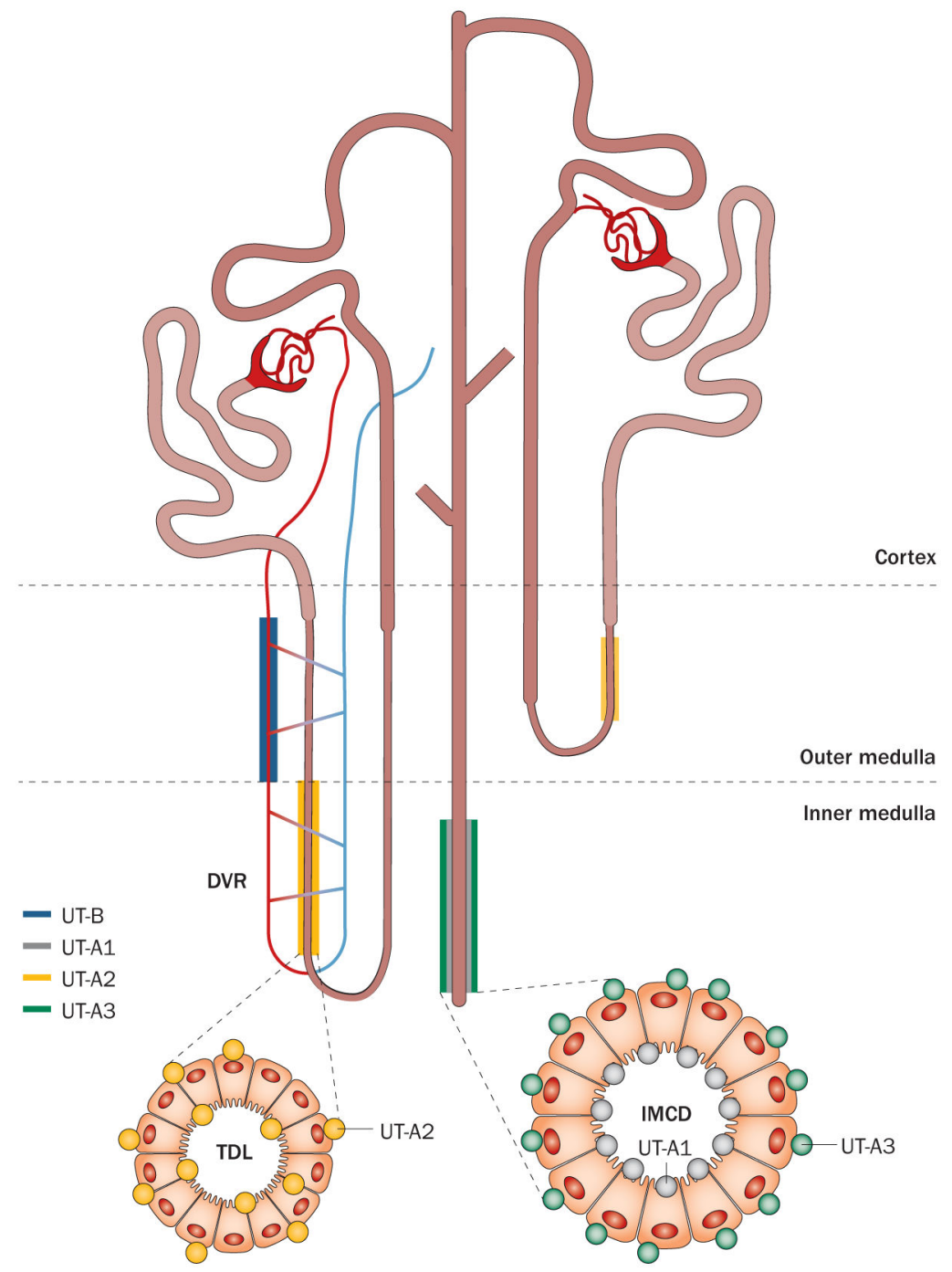

Figure 3.

Expression of the major mammalian UT isoforms in the kidney. Abbreviations: DVR, descending vasa recta; IMCD, inner medullary collecting duct; TDL, thin descending limb of Henle; UT, urea transporter. 
a Epithelial cell layer Enzymatic urea assay
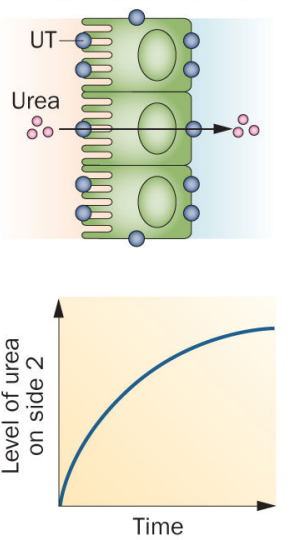

d Adherent cell layer High-throughput
cell volume assay by fluorescence

UT-A1 AQP1

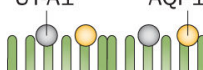

b

Stopped-flow light scattering

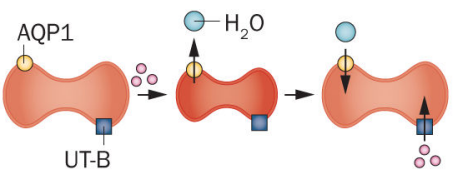

$\downarrow$ UT-B inhibitor concentration $(\mu \mathrm{M})$

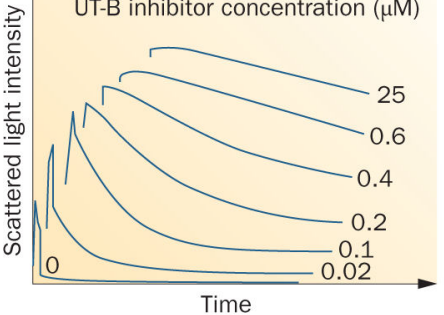

Time

c

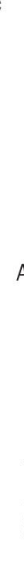

Erythrocyte suspension
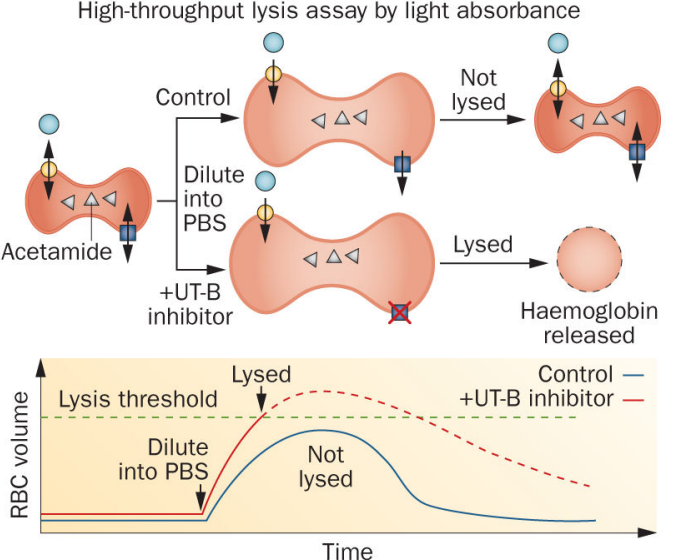

Figure 4.

Assays of UT-mediated urea transport. a | UT-mediated transport increases urea levels on side 2 over time. b | UT-B inhibition prevents cell reswelling after shrinkage. Scattered light intensity decreases as cells swell (bottom), and swelling kinetics are slowed with UT-B inhibition. c| UT-B inhibition impairs acetamide exit in an isosmolar external buffer, leading to lysis when water entry increases erythrocyte volume beyond a threshold (bottom). Dashed curve shows the hypothetical progression of erythrocyte volume without lysis. $\mathbf{d}$ | An inwardly directed urea gradient causes water efflux and cell shrinkage, detected as reduced YFP fluorescence. UT-A1 inhibition slows subsequent cell swelling, detected as an increase in YFP fluorescence. Abbreviations: AQP1, aquaporin-1; PBS, phosphate-buffered saline; RBC, red blood cell; UT, urea transporter; YFP, yellow fluorescent protein. Permission obtained for parts $\mathrm{b}$ and $\mathrm{c}$ from the Federation of American Societies for Experimental Biology ( Levin, M. H. et al. FASEB J. 21, 551-563 (2007). Part d reprinted from Chemistry \& Biology 20, Esteva-Font, C. et al., A small molecule screen identifies selective inhibitors of urea transporter UT-A. 1235-1244, () 2013, with permission from Elsevier. 
a

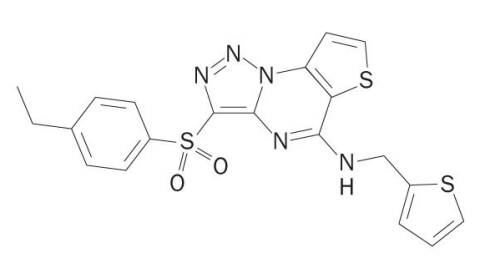

b

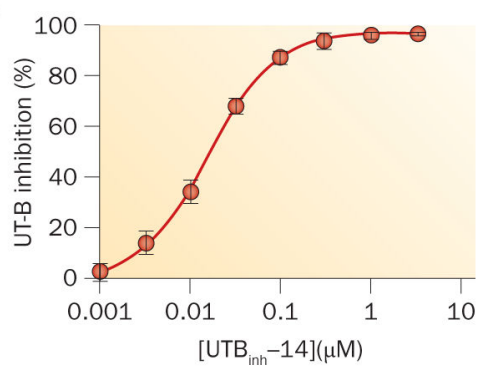

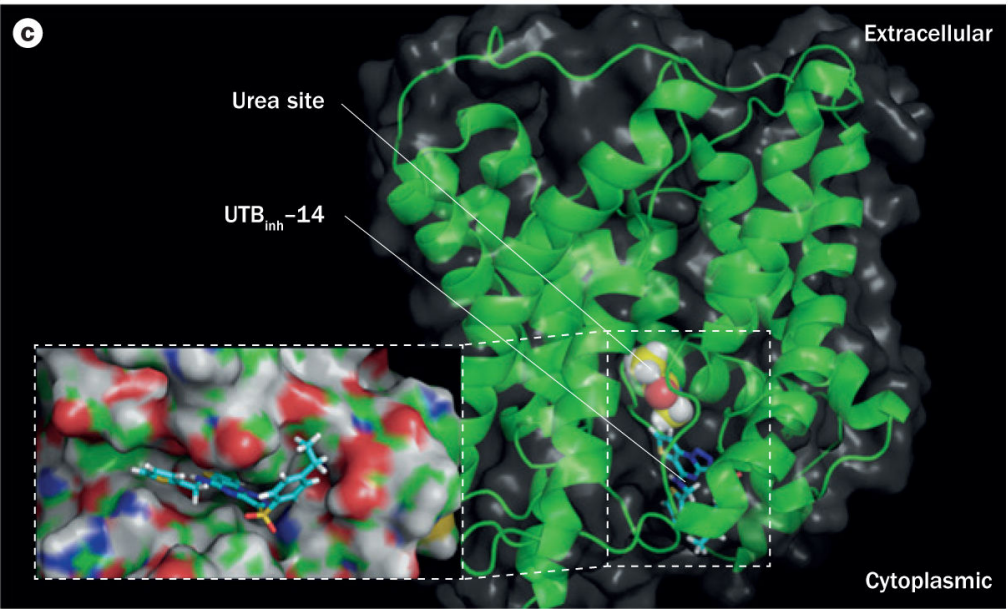

Figure 5.

$\mathrm{UTB}_{\text {inh }^{-1}} 14$ inhibition of UT-B. a $\mid$ The chemical structure of $\mathrm{UTB}_{\text {inh }}-14$. b $\mid$ Concentrationinhibition data for $\mathrm{UTB}_{\text {inh }}-14$ inhibition of human UT-B that shows an $\mathrm{IC}_{50}$ of $10 \mathrm{nM}$ when fitted to a single site inhibition model. $\mathbf{c} \mid$ Docking of $\mathrm{UTB}_{\text {inh }}-14$ shown in a homology structural model of human UT-B, showing UTB inh $^{-14}$ binding at the cytoplasmic surface. The computed binding site of urea analogue dimethylurea (yellow) is shown. The inset shows a magnified view of $\mathrm{UTB}_{\text {inh }^{-1}} 14$ bound in a groove at the UT-B channel region.

Abbreviations: inh, inhibitor; UT, urea transporter. Permission for part $\mathrm{b}$ obtained from the American Society of Nephrology (C) Yao, C. et al. J. Am. Soc. Nephrol. 23, 1210-1220 (2012). 
a<smiles>CCOc1ccc(Nc2cc(C(=O)N3CCCCC3)nc3c(OC)cccc23)cc1</smiles>

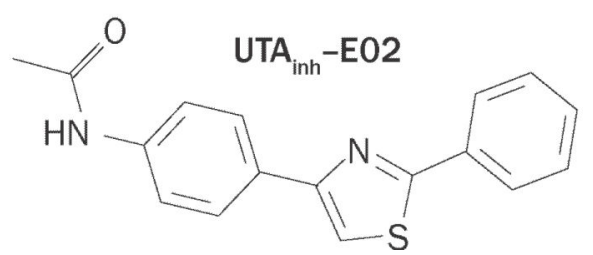

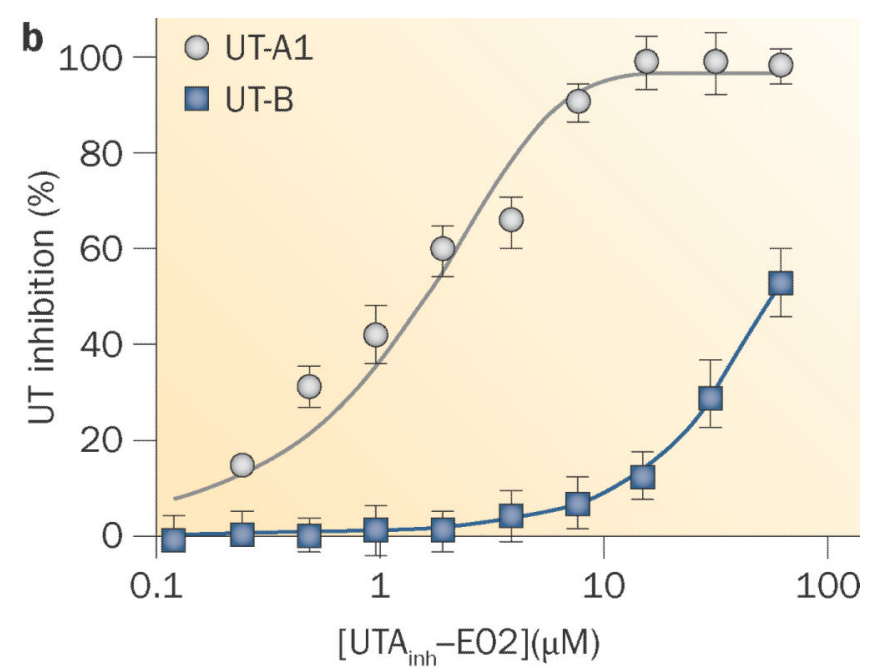

Figure 6.

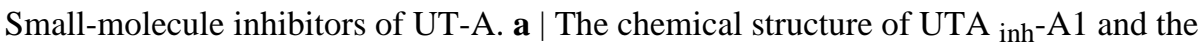
chemical structure of $\mathrm{UTA}_{\text {inh-E02. }}$ - b $\mid$ Concentration-inhibition data for $\mathrm{UTA}_{\text {inh }}$-A1 inhibition of UT-A1 and UT-B urea transport. UT-A1 inhibition exhibits an $\mathrm{IC}_{50}$ of $1-2 \mu \mathrm{M}$, approximately 100 -fold higher than the $\mathrm{IC}_{50}$ it exhibits for UT-B inhibition. Abbreviations: inh, inhibitor; UT, urea transporter. Permission for part $\mathrm{b}$ obtained from the Federation of American Societies for Experimental Biology (C Esteva-Font, C. et al. FASEB J. 28, 38783890 (2014). 

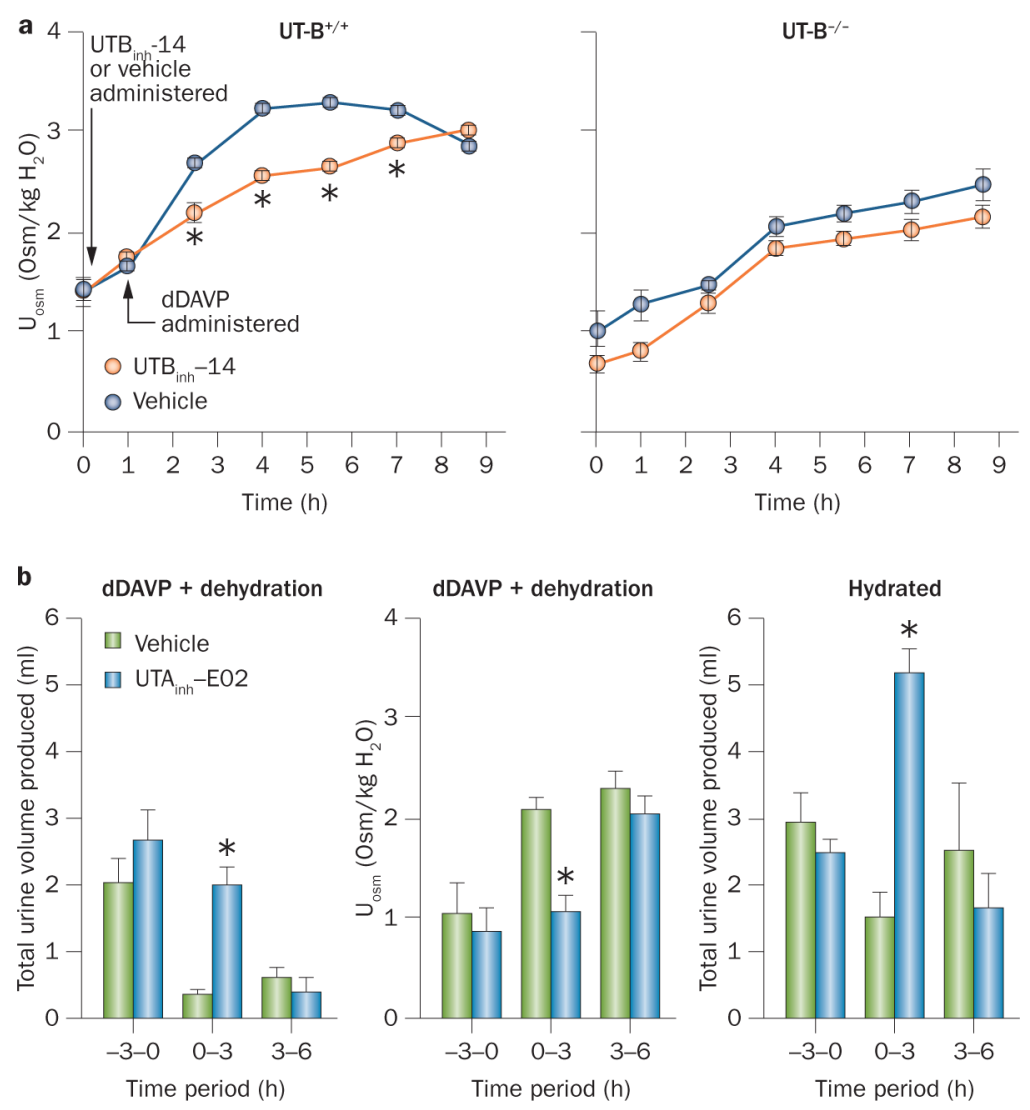

Figure 7.

UT inhibitor diuretic action in rodents. a $\mid \mathrm{UTB}_{\text {inh }^{-14}}(300 \mu \mathrm{g})$ mildly reduces urine osmolality in wild-type mice after dDAVP administration (left graph; mean \pm S.E., 6 mice per group). dDAVP and $\mathrm{UTB}_{\text {inh }^{-1}} 14$ have no effect in UT-B knockout mice (right graph). b | dDAVP (intraperitoneal, $4 \mu \mathrm{g} / \mathrm{kg}$ every $3 \mathrm{~h}$ ) and dehydration produces maximal urinary concentration. $\mathrm{UTA}_{\text {inh }}-\mathrm{E} 02(5 \mathrm{mg})$ administered by intravenous injection at time 0 prevents the effects of dDAVP on urine volume (left graph) and osmolality (centre graph) (mean \pm S.E., 4 rats per group). The same effect is seen in hydrated rats (right graph; mean \pm S.E., 3 rats per group. * indicates $P<0.01$. Abbreviations: dDAVP, desmopressin; $\mathrm{U}_{\mathrm{osm}}$, urine osmolality; UT, urea transporter. Permission obtained for part a from the American Society of Nephrology () Yao, C. et al. J. Am. Soc. Nephrol. 23, 1210-1220 (2012) and for part b from the Federation of American Societies for Experimental Biology (๑) Esteva-Font, C. et al. FASEB J. 28, 3878-3890 (2014). 